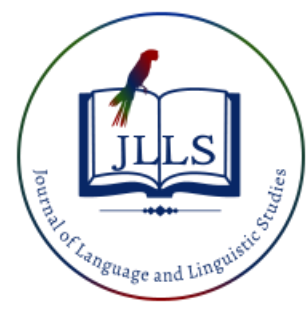

Available online at www.jlls.org

JOURNAL OF LANGUAGE

AND LINGUISTIC STUDIES

ISSN: 1305-578X

Journal of Language and Linguistic Studies, 17(2), 971-982; 2021

\title{
Digital discourse of English language acquisition
}

\author{
Nataliia Lazebna $^{\text {a }}$ iD, Anatoliy Prykhodko ${ }^{\text {b1 }}$ iD \\ ${ }^{a}$ Zaporizhzhia Polytechnic National University, Zaporizhzhia, Ukraine \\ ${ }^{b}$ Zaporizhzhia Polytechnic National University, Zaporizhzhia, Ukraine
}

APA Citation:

Lazebna, N., Prykhodko, A. (2021). Digital discourse of English language acquisition. Journal of Language and Linguistic Studies, 17(2), 971-982. Doi: $10.52462 /$ jlls.67

Submission Date:12/03/2021

Acceptance Date:30/05/2021

\begin{abstract}
This paper focuses on the use of modern technologies and the Internet in ESL learning. In the modern world of technology, language-learning processes transform into interactive activities, involving different technical tools and methods. Based on recent researches and studies in this field, implementation of media, audio, and visuals during classes improves cooperation between a teacher and students thus creating an interactive and technologically oriented cooperation atmosphere. The technologically perceptive environment in the classroom facilitates the ESL learning process thus improving and strengthening students' gained knowledge and enables their active participation during classes. Practical strategies of technology implementation, broadcasting of video during classes, representing related website addresses, and many other features of special tactics implementation in the ESL learning process are in the focus of this research paper. A special concern of this study considers the role of the Internet in the modern ESL learning process as an effective tool for information search and communication improvement during classes. Web searching tactics and strategies are of vital importance for modern ESL learners. Therefore, the development of students' creativity and imagination, facilitation of the learning process, and active engagement of both a teacher and students can be the result of effective technology implementation in the ESL learning process.
\end{abstract}

Keywords: discourse; visuals; computer technology; interactivity; reading and writing skills.

\section{Introduction}

This paper focuses on the use of modern technologies in the process of ESL learning. The global world is developing and setting its own rules. The contemporaries should follow them to keep updated. The role of the Internet and computer technologies is evident and determines the process of English language learning. Interactivity, effective cooperation between teachers and students, as well as the use of audio files and video clips during ESL classes, leads to effective learning. The vocabulary enrichment, training of grammar skills, and other language learning activities lead to successful ESL learning.

The implementation of ICT, visuals, the Internet searching strategies, - these and other issues are considered further in this research paper. This is another attempt to highlight the important role of

\footnotetext{
${ }^{1}$ Corresponding author.

E-mail address: aprykhod777@gmail.com
} 
technology in the modern world. The context of education is one of the most challenging and intriguing backgrounds of human activities. There is no doubt that modern teachers and students should be able to cooperate and mediate their relationship with the help of the Internet and ICT.

Communication skills development is a challenge for modern ESL students. To improve the students' communication skills, there is a need for multimedia technologies, video and audio streams, and a teacher's assistance during classes. The implementation of ICT, visuals, video clips, and other types of media during ESL classes is a key concern for the following study. The focus is video films and clips simulating the native-speaking environment, which is an important background for the efficient teaching of Ukrainian students.

\section{The objective and Research Questions}

In terms of the research, the authors focused on the implementation of modern technologies during English language classes. The first step is to use authentic video courses and video equipment, which enable the teacher to use various technologies in working with video films. They help to simulate situations in which language learning takes place within the cultural environment of native speakers. The questions of this study are:

1. Does a technology of dramatizing and simulating episodes from movies, which are interesting for the students, are effective in teaching them techniques of communication, mastering verbal etiquette, and improving English communication skills?

2. Does a video representation of a native speaker's life helps the ESL students to develop their cross-cultural awareness (for example, to focus on their cultural background, implement cross-cultural knowledge and penetrate into the native-speaking environment)?

3. Does the implementation of innovative media technologies during foreign language classes increases the motivation and cognitive activity of students of all ages and broaden their horizons?

\section{Method}

This study focuses on the latest researches and studies in the field of technology implementation in the modern learning context. The implementation of ICT, visuals, video clips and other types of media during ESL classes is a key concern. Recent data, reports, relevant studies, findings of the scientists, which are reliable and based on the empirical background, are effective for students' demonstration and development of their skills and knowledge in the field of ESL learning. Further, the study represents the results of the practical use of the ICT and media implementation experiment during classes for the graduate students of Zaporizhzhia National Polytechnic University.

Participants Fifty students of the fourth year of education, obtaining the Bachelor's degree in Translation, aged 20-21 years old, both males and females, the Ukrainians. They visited classes of the English language and Translation for a year and watched video courses, created PowerPoint presentations, listened to the audio files, searched the Internet and filled in the data of the questionnaires representing the results of their learning. The evaluation of their final grades and the answers to the questionnaires reflect a viable empirical basis for the research. The improved academic progress during English classes is evident proof of the modern technologies implementation efficiency in ESL learning.

\section{Discussion}

The use of computer presentations in the educational process intensifies mastering the learning material by students and advances teaching to the qualitatively new level, using the multimedia 
projector or provide the information to the students via their computers connected in one network. Moreover, computer presentations allow you to focus students' attention on significant moments of the information presented and create visual images in the form of illustrations, diagrams, and graphics and so on. The presentation enables a teacher to influence several types of memory: visual, auditory, emotional and even motor perception.

This leads to active participation in the learning process thus facilitating the process of information perception and memorization of educational material. If the lesson contains a large amount of illustrative material, the use of a computer presentation will significantly improve the effectiveness of it. The computer is not constantly used during the lesson, but serves as a means for information search, the stimulus for the formation of speech examples. With the help of a computer presentation during the lesson, the students can increase their motivation, to use a large amount of illustrative material, to be involved in the independent process of training that is especially important for the development of their general educational skills. The computer does not replace the teacher during the lessons of a foreign language, but it is an effective assistant, which allows improving the quality of training and the effectiveness of control during classes. Therefore, using even the most advanced multimedia products cannot replace live communication in the classroom. For example, a student can develop a PowerPoint presentation focused on the selected topics. A wide range of multimedia products, computer technologies, the Internet and other media is a key to success in ESL learning in Ukraine. The modern teacher should look far beyond the use of a communicative approach, listening comprehension, or electronic vocabularies used during classes (Almekhlafi, 2006).

To create a positive and friendly atmosphere, each ESL teacher can develop his own strategy of teaching. The motivation for learning English is another important condition, which needs constant improvement and fostering. From reading to writing, from listening to speeches, each student can find the best approach to his own most convenient and comfortable learning (Ebedy, 2015). According to one of the recent researches in this field, "Students' approaches to Internet research vary greatly, but most are able to complete Web-based research tasks. However, the quality of most students' performances can be greatly improved" (Eagleton, 2003). Therefore, a teacher should play the role of an assistant and mentor for students, who will direct their actions during web searching, collecting of the material, and implementation of knowledge used.

For example, "Muzzy in Gondoland" is an animated video course about a friendly monster from outer space, where he meets new friends, the king and the queen, the princess Sylvia and the gardener Bob. Another character, Norman, who lives in the clock tower, explains the most difficult moments in a foreign language. This video course is correlated with the English knowledge of the elementary level and the students from Ukraine will be able to foster their understanding of language and use it in practice. A practical implementation of this course will foster communication skills, logical thinking and the ability to self-expressing.

Another effective course is a rich informative video course about the journey of a young couple in Britain providing useful practical language information and expands background knowledge related to the history, culture, art, geography of the country. This is a broad representation of a person's ability to focus on his cultural background, implementation of cross-cultural knowledge and a student's


course that covers the range from the beginner level (1 to 30 lessons) to the level of free communication on everyday topics (31 to 60 lessons). It includes entertaining, dramatic, and documentary episodes. "Family Album, USA" shows the story about the Stewart family and introduces the modern American culture, traditions, and relationships among people drawing attention to the peculiarities of the American version of the English language (2010). 
"Everyday conversation in English" focuses on the impressions of a foreign student who came to Britain and started living with the Harrison family. These two abovementioned videos concentrate on the cultural awareness of the students. We think that not only communication skills are important for students, but also their ability to use them in practice. Therefore, the first step is to introduce these video courses during classes. We believe that authentic video materials in English will be interesting for the students and make the lessons more diverse, entertaining and informative.

Another step is to implement multimedia training manuals. The implementation of innovative media technologies during foreign language classes increases the motivation and cognitive activity of students of all ages and broadens their horizons. An effective tool for providing a multilevel and individualized approach to teaching is to use electronic teaching tools. E-learning tools provide students with greater opportunities for interaction during classes (Thakur \& Al-Mahrooqi, 2015). Based on the students' knowledge, it is possible for a teacher to choose an acceptable level of complexity. The electronic tools benefit saves time. For example, hyperlinks help not just translate a word but reveal the meaning of the concept fully. The electronic materials are more interactive than printed ones due to the option of navigating through the information space of the manual using the menu. The electronic manuals containing interactive games or animation help to solve the problem of motivation. Students delve into the atmosphere of amusement, and they can complete a great variety of tasks, change their activities, or even practice creative elements. In such a way, the process of learning process optimization is evident.

The following multimedia manuals are the most effective in English language classes. "Professor Higgins. English without an accent" is a helpful course, which focuses on phonetics. Students follow the articulatory movements looking at the computer screen and perceive the right intonation by ear. The similar technology one can find in BBC learning class of phonetics, which enables a student to focus on a speaking woman from the video, focus on the transcription and repeat the words sounding. "English basic course" contains about 60 texts for listening focused on the topics in history, culture, the life of the United Kingdom and the United States. Different online dictionaries, glossaries, databases will enable the students to listen to the correct pronunciation of the word and to improve their phonetic skills.

The following table represents the data found in the process of this study.

Table 1. The video courses effectiveness for ESL students

\begin{tabular}{|l|l|l|}
\hline No & \multicolumn{1}{|c|}{ Name of the video course } & \multicolumn{1}{c|}{ Skills Developed } \\
\hline 1 & "Muzzy in Gondoland" & $\begin{array}{l}\text { Communication skills, logical thinking, the } \\
\text { ability of self-expressing }\end{array}$ \\
\hline 2 & "BBC Essential English Guide to Britain" & $\begin{array}{l}\text { Background knowledge, culture, art, the } \\
\text { geography of the UK }\end{array}$ \\
\hline 3 & "Follow me" & $\begin{array}{l}\text { Cross-cultural knowledge, communication } \\
\text { skills }\end{array}$ \\
\hline 4 & "Family Album, USA" & $\begin{array}{l}\text { Knowledge about the American culture, } \\
\text { traditions, relationships between people, } \\
\text { communication skills }\end{array}$ \\
\hline 5 & "Everyday conversation in English" & $\begin{array}{l}\text { Cultural awareness, communication skills, } \\
\text { critical thinking }\end{array}$ \\
\hline 6 & "Professor Higgins. English without an & $\begin{array}{l}\text { Speaking skills, phonetics improvement, } \\
\text { intonation, and pronunciation }\end{array}$ \\
\hline 7 & "English basic course" & $\begin{array}{l}\text { Knowledge of history, culture, the life of the } \\
\text { United Kingdom and the United States, } \\
\text { communication skills }\end{array}$ \\
\hline
\end{tabular}


Following the ideas of Xiaoning (2007) and the article "On the Use of Video Clips in College English Teaching/ utilization du video clip dans l'enseignement de l'anglais universtaire", video clips should be implemented during English language classes as a helpful tool facilitating the process of learning. The use of visual media, such as multimedia equipment, demonstration of video clips and films, foster a teacher's ability to withstand the challenges of the innovative learning process and are required for further success. We intend to implement one of the following video clip sessions with the commentaries (Village Voices, Global Visions Miller \& Borowicz's (2005), City Voices, City Visions projects). With the help of these video clips, teachers can outline the general theme of the lesson, appropriate commentaries, and related texts. The students reacted in the following way, "they presented, defended, and discussed their storyboard ideas with mediation from the teacher. Students negotiated and agreed on an idea and assigned roles (director, scriptwriter(s), movie and music editors, camera person, staging, actors, and so forth), all in the foreign language" (Almekhlafi, 2006).

The ESL students can lack appropriate knowledge, and visuals can assist them in better understanding. Another perfect option to involve the students in the learning process through technologies is to use their laptops. For example, with the help of Macs, the students can switch languages and the teacher can recommend using the English language only. Video techniques implemented in the learning process are known as, "multimodal, experiential, and hands-on, involving multiple senses and drawing on multiple intelligence. It bridged traditional and new literacies and fostered foreign language and content learning, technology skills, and critical thinking with regard to power in interlocking structures of class, language, culture, and the environment" (Pino-Silva, 2007).

Therefore, the implementation of different visual strategies in the process of learning is acknowledged around the world. There are much more advantages than the facilitation of the learning process because the students are getting acquainted with the foreign culture and can be aware of peculiarities of the culture of England from these video clips or films. Moreover, presentation of different video clips or films in terms of the programs of Village Voices or Global Visions, students' knowledge was extended and they were dealing with transformative learning (Goulah, 2007). Nevertheless, visuals should not be considered as the only effective or correct practice in the process of English learning as a second language. It is possible to claim that in many underdeveloped countries there is a lack of video or audio resources, which are available for the students in their learning process. These are the major limitations for teachers not to implement their strategies in the language learning processes.

Moreover, information and communication technologies are key to successful ESL learning. Technologies can save time and effort for both teachers and students. Improvement of cooperation between teachers and students depends on the effective implementation of ICT in the process of learning. In the majority of researches and studies, the effectiveness of ICT is discussed concerning the fields of business and management. There are a few works focused on the implementation of ICT in the process of learning, especially ESL learning. In the modern educational paradigm, the communicative approach and the development of vocabulary with the help of technologies are two important factors.

In terms of the National Curriculum, ICT development and implementation in the learning process fosters and improves computer students' skills and abilities. Consequently, the students will be able to use effectively the knowledge they gained during their learning process. During ESL classes, such media tools as audio records, video clips and movies, and creative PowerPoint presentations can diversify the learning context of the students. They can find any appropriate and available option for a demonstration of their technical, writing, reading and linguistic skills. Therefore, there is a general tendency in education to implement ICT in the process of ESL learning. Strategic management and 
whole-school plan combined with investments in ICT can make these technologies effective and useful in the process of learning.

Further, this research focuses on the necessity of information search and availability of the latest information as important factors on the way to students' decision-making abilities and web-search strategies development. ICT creates global bridges and enables students' communication across the world. With the help of modern ICT, the students and teachers can reach their curriculum goals. Therefore, from the global perspective, technological tools mediate cooperation between teachers and students, their teaching and learning capabilities.

Another option of ICT implementation is the function of monitoring, recording, assessing and reporting. Therefore, ESL teachers can implement ICT as an effective tool for the evaluation of students' success. Appropriate ICT management leads to the improvement of students' performance. There is an option to take control of the efficiency of ICT by means of interviewing during the learning process. Of course, both, teachers and students need appropriate knowledge and skills for effective implementation of ICT.

ICT implementation cannot be a panacea for the curriculum. If students have access to various information resources, they will rely on the sources rather than on their own creative thinking abilities and initiative. At this point, the ESL teacher plays a crucial role, because he/she can determine the effective role of the Internet. "Unless teachers are given recognition for the key role that they can play, they will continue to be gatekeepers of classroom change and prevent themselves from being able to focus on the key issues that really matter" (Badke, 2009). Teachers are mediators and effective leaders in the learning process. Students would follow their leaders in case of the interesting and diversified representation of the curriculum.

The students are too young and inexperienced and they cannot evaluate the role of the Internet appropriately. Teachers should help the students to choose from appropriate information content provided by the ICT. Students should be able to select and analyze relevant information and implement it effectively in their learning process. Therefore, the vital role of ICT is beyond any doubt. Modern technologies and computers surround the students. There is a number of steps taken by the students to select and use appropriate information, enrich their knowledge with the help of various sources available. ICT is not a tool for plagiarizing, and it is not a means for cheating. The real goal of ICT is to enrich students' knowledge and expertise, make them technically perceptive, creative and analytical.

The use and implementation of ICT in English classes facilitate the learning process. Teachers intend to use computer technologies during different classes in all subjects. ICT open access to new sources of information, increase the effectiveness of individual work, give new opportunities for creativity, gain and consolidate professional skills, and enable the implementation of fundamentally new forms and methods of teaching. Consequently, teachers of English appreciate ICT in the learning process as effective tools for their teaching methods implementations.

As far as we can see, in terms of the modern methodological paradigm, teachers choose a communicative approach. According to many researchers, the advent of the computer can solve the problem of effective communication in class. With the use of the latest developments in the field of ESL learning, multimedia technology implementations in the learning process cannot fully substitute virtual communication with- face-to-face communication.

There are several advantages of ICT in ESL learning:

1. ICT creates a favorable psychological climate thus increasing the motivation for learning English. 
2. Methodical advantages of ICT training enable both teachers and students to work more effectively with a greater degree of interactivity during classes. Moreover, the rate of mastering grammatical structures and the development of vocabulary when learning ESL with the help of ICT increases by two-three times.

3. Technical advantages of teaching and learning English with the help of ICT. For example, the students can use some options of technical translation, grammar, and spelling checkers, the use of multimedia, and interactive video during teaching and learning oral speech. The educational value of computer networks, which connect several machines in one educational institution, and globally, is invaluable.

4. Raising the professional level of teachers. Despite all the advantages, the huge potential of ICT has some problems. This method of teaching is rather innovative and it is necessary to develop a teacher's skills and students' knowledge in the process of ICT implementation. Of course, educational institutions can lack professional equipment or high-quality software.

There are no clear standards and criteria for evaluating the effectiveness of ICT implementation in ESL learning. There are possible options for ICT implementation in ESL learning.

1. Systematic use of information technologies as helping teaching instruments and tools.

2. Fragmentary use of ICT during ESL classes.

3. Implementation of the entire ESL training course using ICT.

Thus, we can offer the following options for using the tools of ICT in the process of teaching ESL.

1. Conducting current and final test sessions (related to topics, chapters, courses) with the help of diagnostic or test programs in vocabulary and grammar.

2. The use of pedagogical software as a means of new vocabulary or grammatical material implementation.

3. The use of software tools (IPS), such as directories, dictionaries, or spell-checking programs. In such a way, the students will be able to perform independent creative tasks, translations, analytical reading and other types of activities. A teacher can use these instruments as a tool for creating tests, training programs, evaluation of students' performance and so on.

Modern computer technologies are used today in all spheres of human activity. Training a specialist in any field of knowledge includes at least compulsory user learning. Computer literacy becomes one of the components of the modern understanding of an educated person. That is why today it is necessary to pay serious attention to using the means of new information technologies in teaching English (Alternative English Teaching Methodologies, 2010).

Modern teachers claim that in a technologically competent and Internet-mediated environment it is easier for them to create a friendly and effective learning atmosphere because ESL students feel much comfortable. Different types of media and a great variety of technical tools enable the students to get knowledge in a more comprehensible way. For example, during ESL classes one of the main tasks for teachers is to help students with their pronunciation improvement. Therefore, teachers should use not only books but also turn on audio and video files to refer to the pronunciation of native speakers (Thakur \& Al-Mahrooqi, 2015). Xiaoning (2007) suggests the use of video clips during ESL classes. At the same time, the researchers claim that a video clip should not last more than 3-5 minutes (Zaki, 2015).

According to (Almekhlafi, 2006), the role of e-learning methods cannot be overestimated. Video materials can be effective in the process of learning. Both, for a teacher and the class video materials, can be entertaining and useful. For example, during classes of phonetics or phonology, ESL students require a complex of teaching methods. There is a great barrier in the way of video materials 
implementation during classes. Teachers from developing countries have no access to external support or financing (Ebedy, 2015). The modern researchers claim that it is necessary to cooperate with teachers and students. Teachers should involve their students in the learning process effectively (Bamanger \& Gashan, 2014). It is possible to find common points between teachers and students in the process of video materials discussion.

Another important skill to teach students is web search. An effective tool is the students' ability to make notes. The best strategy for the Internet search for students is a selective note-taking strategy. The students should be proficient in the Internet access ability. They should learn alternative strategies and use information effectively. The information search improves students' abilities in creative writing, reflective writing, synthesis, and analysis of their ideas. Appropriate citation and synthesis play a crucial role in the process of learning. Citation formats can be different and it is difficult for the students to develop this ability. The students should be able to find relevant information sources, process and analyze them. Web search is one of the required stages on the way to successful learning. It is an effective vehicle, which informs and develops a student's learning skills. It is difficult for ESL students to find the appropriate resources and they can jump from one website to another. They cannot find golden information means. Another challenge for students is to jump from one site to another because they can be easily confused. A teacher should underline the dominance of the student's own creative ideas about the essence of creative writing and use the Web as just a background for their ideas' development. There is a slight difference between research skills and creative writing. To improve the situation, the ESL teacher should compose research questions to facilitate the process of information search. Moreover, there are many challenges on the way to students' appropriate information search. They have no skills of referencing and synthesizing, lack literacy or technology skills, and come across technological challenges of the Web sites.

ESL students should be professional enough to conduct Internet research and the students should use the Web effectively. The constant assistance of the librarians and teachers improves the students' ability of information skills development. The creation of a friendly atmosphere and effective cooperation in the classroom facilitates the process of the information search. Students have different skills and abilities. The same is about information searching skills and strategies. "Students' approaches to Internet research vary greatly, but most are able to complete Web-based research tasks. However, the quality of most students' performances can be greatly improved" (Eagleton, 2003). The teacher should follow these steps in the process of information search teaching. A teacher should be able to improve his teaching methodology in terms of e-learning. Web search is one of the integrative parts of this process. For ESL students, it is another challenge to learn web search skills. Therefore, in the modern educational context, modern teachers should be able to focus on background knowledge, language, and computer skills. The improvement of a student's literacy skills and development of vocabulary represents a holistic background for the successful implementation of web search skills.

An effective web search is a helpful tool in the process of creative writing. The Internet helps in the formation of conversational, communication and speech skills. Teachers can implement web resources and the Internet in teaching vocabulary and grammar. Moreover, the Internet helps ESL students in the development of analysis, synthesis and object thinking. The Internet is developing social and psychological qualities of teaching and improving students' confidence in themselves and their ability of group cooperation. During classes, the mode of interactive communication prepares students for real-life experiences. It is very useful to create some challenging life situations and see the way students react to them and respond in English.

At this point, a teacher can consider the language competence of the student. Even if there are too many mistakes, it is very helpful if a student can focus on his mistakes and find the best solution. With the help of the Internet, the students can observe and copy the use of language, foreigners' skills, and 
their behavior patterns and look for new solutions to their problems. Another effective means of communication between teachers and students is electronic mail. With the help of this type of communication, a teacher can build an effective communicative bridge with his students. The Internet removes the cultural limits and bridges between nations. Teachers help their students to be interactive and open-minded. The following table represents the most effective types of media and the Internet resources and skills developed.

Table 2. The Video Courses Effectiveness for ESL Students

\begin{tabular}{|c|c|c|}
\hline № & Name of the media & Skills Developed \\
\hline 1 & $\begin{array}{l}\text { True-to-life navigating subway websites } \\
\text { http://www.subwaynavigator.com } \\
\text { http://www.metrostlouis.org }\end{array}$ & $\begin{array}{l}\text { Geographical position and location of } \\
\text { students' in the UK/America }\end{array}$ \\
\hline 2 & $\begin{array}{l}\text { "Learning English" } \\
\text { www.bbc.co.uk/worldservice/learningenglish/general }\end{array}$ & $\begin{array}{l}\text { The British accent, complex development } \\
\text { of pre-intermediate and intermediate levels } \\
\text { students' linguistic skills }\end{array}$ \\
\hline 3 & $\begin{array}{l}\text { The Voice of America website } \\
\text { http://www.voanews.com/learningenglish/home/ }\end{array}$ & $\begin{array}{l}\text { The American English, reading, speaking } \\
\text { skills }\end{array}$ \\
\hline 4 & $\begin{array}{l}\text { ESL Podcast website or English as a Second Language } \\
\text { Podcast http://www.eslpod.com }\end{array}$ & $\begin{array}{l}\text { Linguistic and communication skills of } \\
\text { ESL students }\end{array}$ \\
\hline 5 & $\begin{array}{l}\text { The American English website } \\
\text { http://effortlessenglish.com }\end{array}$ & Phonetics, speaking skills \\
\hline 6 & Randall's ESL Cyber Listening Lab http://esl-lab.com & Reading, speaking skills, phonetics \\
\hline 7 & YouTube website http://www.youtube.com & $\begin{array}{l}\text { Complex linguistic skills, reading, writing, } \\
\text { listening comprehension, communication }\end{array}$ \\
\hline 8 & Computer-Assisted Language Learning (CALL) & Linguistic and technological skills \\
\hline 9 & Interactive multimedia (IMM) & $\begin{array}{l}\text { Interactive e-learning and development of } \\
\text { linguistic skills }\end{array}$ \\
\hline 10 & Mobile-Assisted Language Learning (MALL) & Writing skills improvement \\
\hline
\end{tabular}

For this purpose, it is very popular to teach the students real-life experiences. There is a wide range of popular websites, which can help students to adapt to life realities. For example, true-to-life navigating subway websites (http://www.subwaynavigator.com) or (http://www.metrostlouis.org). With the help of these websites, students can travel around the world's largest cities by subway. The English names of stops, the approximate travel time, routes and stations, - these and other materials are available in English.

Another helpful resource for English learners is the BBC website. The section of the website "Learning English" (www.bbc.co.uk/worldservice/learningenglish/general) is valuable and helpful in the process of ESL learning. This resource can be difficult for students with pre-intermediate and intermediate levels. Different audio files for the students are available in the British variant of pronunciation. Another web source widely used and popular among the students is the Voice of America website (http://www.voanews.com/learningenglish/home/). The students can find available material on the website organized into thematic sections. This website provides the audience with the American variant of pronunciation. Another website is the ESL Podcast website or English as a Second Language Podcast (http://www.eslpod.com). This is a great website for ESL students. They can listen to podcasts both online and download them to the player, phone, etc. New podcasts in English are constantly added to the website.

Another popular website, which promotes the American version of the pronunciation, is the website http://effortlessenglish.com. The author of teaching methodology is A. J. Hoge an honored teacher of English. Another website is Randall's ESL Cyber Listening Lab (http://esl-lab.com). All audio clips on 
the website are available in three groups according to the level of complexity. Each clip is accompanied by the text, a set of tasks, as well as an explanation of individual words and expressions in the English language. These websites can help students to enrich their speech with useful expressions.

Of course, another important source is the YouTube website (http://www.youtube.com). Teachers can find a wide range of sources on this website. YouTube offers you the opportunity to find audio materials of any level of complexity. The records of the most interesting lectures and seminars, different classes and other materials one can find on this web source. For more advanced English language learners, the numerous educational channels of English-speaking universities and institutions are available on YouTube.

Teachers can implement multimedia learning courses and implement them with their course books, e.g. College English (the publisher is Shanghai Foreign Language Education Press, New Horizon College English published by Foreign Language Teaching and Research Press and others). Students can find innovative ideas in these course materials.

Computer-Assisted Language Learning (CALL) is another technique implemented in the learning process. The use of interactive visuals and interactive multimedia (IMM) is another concern for such studies. The benefits of e-learning are obvious. With the help of CALL, modern teachers can mediate their teaching strategies. If teachers implement different strategies of e-learning in the learning process, they can integrate audio and visual means in their lessons. The CALL strategies led to positive results for Japanese students in the process of ESL learning. Gradually, these students learned the structure of the English language, its content, improved their technological skills and launched their own projects. "MALL differs from CALL in its use of personal, portable devices that enable new ways of learning, emphasizing continuity or spontaneity of access and interaction across different contexts of use".

Of course, very often colleges and universities are interested in interactive program implementation to the earning processes, but there are many factors, which prevent these strategies of implementation. Very often teachers invent something and implement the most available visuals, such as tables or posters. These are simple, but rather effective methods too. Looking at these visuals, a student can better memorize a new word or information about a certain phenomenon or event. Activation of visual channels in the minds of the students is as much effective as triggering audio channels in their minds. If all "ways" to reach the students' minds are activated, then it is possible to contribute much to the students' knowledge (Ariani, 2016). Therefore, the students should watch this video segment, then react to it, plan their answer and organize their thoughts and integrate both listening and writing skills. In the same way, one can say that the video-based short comment is a certain reaction to the content of a video segment, a segment of live broadcasts, a piece of the DVD documentary, etc. Thus, there are many different options for the teachers to select the most convenient and comprehensible form for students' knowledge development.

\section{Conclusions}

ESL teachers should not litter the minds of the students with verb tenses, noun forms, and other grammar horrors. It is better to evoke their imagination, inspire them and apply creative strategies to the learning process (by means of video films, video clips, news, broadcasts, etc.). The class is a fertile background for listening and writing skills development. In this case, modern young learners of English will not only become sound participants of the global society but also turn into proficient language speakers with an extended worldview and well-developed critical thinking skills. Let a teacher of the English language become a discoverer of the global world for his students and for this 
purpose, he needs to put all his efforts into mediation and realization of creative and educational tactics and strategies.

To sum up the main findings of this research paper, one can say that modern technology in ESL learning is effective and informative. Teachers can implement ICT media and technologies in the learning process as innovative tools and methods for the improvement of ESL learning. Focusing on ICT implementation in the process of ESL learning and their effective use defines effective cooperation between teachers and students. Another key concern of this study is the role of video in teaching ESL. Visuals in learning play another important role and enhance students' imagination, creative thinking and demonstration of gained knowledge. Web resources and the Internet are two basic pillars, which sustain the modern learning process.

Therefore, with the help of technologies and the Internet, the modern teacher can facilitate and improve the ESL learning process. Technologically perceptive students can reach success and gain knowledge in a less sophisticated and boring way if their teachers implement innovative teaching methods. The modern ESL teachers should be open to innovations, ready for the experiments, welcoming changes and use technologies in the name of their student's success. To teach grammar and lexis, improve the ways of writing, speaking, and communicating, it is of vital importance to be in the foreground of the modern learning environment. Appealing to the students' creativity, their abilities of critical analysis and interactivity will facilitate the learning process for sure.

\section{References}

Almekhlafi, A. G. (2006). The effect of computer assisted language learning (CALL) on United Arab Emirates English as a foreign language (EFL) school students' achievement and attitude. Journal of Interactive learning research, 17(2), 121-142. Available: https://www.learntechlib.org/primary/p/6218/.

Ariani, M. G. (2016). Beliefs of Iranian Undergraduate El Learners about Language Learning. Modern Journal of Language Teaching Methods, 6(1), 277.

Alternative English Teaching Methodologies, Manila Bulletin, 2010, June 2.

W. Badke, (2009). 'Media, ICT and Information Literacy' Online, September/October, vol. 33, no. 5, pp. $47+$.

Bamanger, E. M., \& Gashan, A. K. (2014). In-Service EFL Teachers' Beliefs about Teaching Reading Strategies. English Language Teaching, 7(8), 14-22. http://dx.doi.org/10.5539/elt.v7n8p14.

Eagleton, M. (2003). Teaching Internet literacy strategies: The hero inquiry project.

Goulah, J. (2007). Village voices, global visions: Digital video as a transformative foreign language learning tool. Foreign Language Annals, 40(1), 62-78. https://doi.org/10.1111/j.19449720.2007.tb02854.x

'Michigan State University Center for Language Education and Research (CLEAR)', Language, Learning \& Technology, vol. 11, no. 1, p. 24+, 2007.

Pino-Silva, J. (2007). The video-based short comment writing task. Foreign Language Annals, 40(2), 320-329. https://doi.org/10.1111/j.1944-9720.2007.tb03204.x

Seifoori, Z., Mozaheb, M. A., \& Beigi, A. B. (2012). A Profile of an Effective EFL Writing Teacher (A Technology-Based Approach). English Language Teaching, 5(5), 107-117. http://dx.doi.org/10.5539/elt.v5n5p107 
Thakur, V. S., \& Al-Mahrooqi, R. (2015). Orienting ESL/EFL Students Towards Critical Thinking through Pictorial Inferences and Elucidation: A Fruitful Pedagogic Approach. English Language Teaching, 8(2), 126-133. http://dx.doi.org/10.5539/elt.v8n2p126

Ebedy, H. G. M. E. (2015). Using Songs in YouTube to Enhance EFL Students' Pronunciation. Occasional Papers in the Development of English Education, 60(2), 51-82.

Zaki, A. A., \& Yunus, M. M. (2015). Potential of Mobile Learning in Teaching of ESL Academic Writing. English Language Teaching, 8(6), 11-19.

\section{AUTHOR BIODATA}

Nataliia Lazebna, Ph.D., Associate Professor at Theory and Practice of Translation Dpt., Zaporizhzhia Polytechnic National University.

Anatoliy Prykhodko Dr. Habil, Professor, Chairman of Theory and Practice of Translation Dpt., Zaporizhzhia Polytechnic National University. 